\title{
OTIMIZAÇÃO DO TEMPO NECESSÁRIO PARA O ENRAIZAMENTO DE MINIESTACAS DE CLONES HÍBRIDOS DE Eucalyptus grandis ${ }^{1}$
}

\author{
Lucas Amaral de Melo², Aloísio Xavier ${ }^{3}$, Haroldo Nogueira de Paiva ${ }^{3}$ e Silvano Rodrigues Borges ${ }^{4}$ \\ RESUMO - Cada uma das fases do processo de miniestaquia é essencial para o sucesso da produção de mudas. \\ O presente estudo teve como objetivo avaliar o tempo para o enraizamento em miniestacas de cinco clones \\ híbridos de Eucalyptus grandis e ajustar modelos que melhor expressem o comportamento dos materiais genéticos \\ durante o processo rizogênico. O processo de enraizamento das miniestacas foi conduzido em casa de vegetação \\ climatizada, e em intervalos de tempo regulares de três dias, foram realizadas avaliações do enraizamento \\ adventício, até o $24^{\circ}$ dia. Pelas análises, foi possível constatar peculiaridades em relação ao comportamento \\ de cada clone durante o enraizamento e concluir que o tempo necessário para o processo difere entre os materiais \\ genéticos, permitindo a identificação do ponto ótimo de enraizamento das miniestacas.
}

Palavras-chave: Miniestaquia, Clonagem e Silvicultura clonal.

\section{OPTIMIZATION OF THE TIME NEEDED FOR MINICUTTINGS ROOTING OF Eucalyptus grandis HYBRID CLONES}

\begin{abstract}
Each phase in the minicutting process is essential for the success of the seedling production. The objective of this study was to assess the time for rooting in minicuttings of five Eucalyptus grandis hybrid clones and to adjust models that best express the behavior of the genetic materials during the rooting process. The minicutting rooting process was carried out in a acclimatized greenhouse and at three-day intervals, adventitious rooting was evaluated until the 24th day. By the analyses, it was possible to verify peculiarities in relation to the behavior of each clone during the rooting period and to conclude that the necessary time for the process differs among the genetic materials, allowing the identification of the best rooting point of minicuttings.
\end{abstract}

Keywords: Cloning, Clonal silviculture and Minicutting.

\section{INTRODUÇÃO}

A importância do gênero Eucalyptus no atual cenário da silvicultura clonal brasileira tem estimulado consideráveis investimentos em pesquisa, o que tem proporcionado melhorias na propagação vegetativa. Diante de algumas limitações quanto à produção e ao enraizamento de alguns clones pelos processos convencionais de estaquia, foram desenvolvidas metodologias de propagação vegetativa que aperfeiçoaram o processo, denominadas de miniestaquia e microestaquia. De acordo com Xavier et al. (2009), essas técnicas proporcionaram a minimização de algumas dificuldades no processo de produção de mudas de certos clones e espécies, principalmente no que se refere ao material adulto, à variação entre clones, a fatores relacionados ao enraizamento e ao desenvolvimento da árvore.

Mesmo com novas técnicas, ainda são observadas diferenças entre as várias espécies do gênero Eucalyptus, bem como entre os clones de uma mesma espécie, quanto

\footnotetext{
${ }^{1}$ Recebido em 17.06.2009 e aceito para publicação em 20.04.2011

${ }^{2}$ Programa de Pós-Graduação em Engenharia Florestal pela Universidade Federal de Lavras, UFLA, Brasil. E-mail: <samelinho@yahoo.com.br>.

${ }^{3}$ Departamento de Engenharia Florestal da Universidade Federal de Viçosa, UFV, Brasil. E-mail: <xavier@ufv.br>e <hnpaiva@ufv.br> . ${ }^{4}$ Programa de Pós-Graduação em Solos e Nutrição de Plantas pela Universidade Federal de Viçosa. E-mail: <borgesilvano@yahoo.com.br>.
} 
ao porcentual de enraizamento. É possível constatar em estudos a grande discrepância entre porcentagem de enraizamento de espécies/clones de Eucalyptus spp., Wendling et al. (2000b) mostraram a variação de enraizamento, num único experimento, de cinco clones híbridos de Eucalyptus spp.: entre 17,2 e 67,2\%. Higashi e Gonçalves (2000) comentaram que resultados encontrados na literatura, quanto ao porcentual de enraizamento de clones de Eucalyptus spp., variam de 0 a 100\%, indicando a ampla variabilidade dentro deste gênero.

A miniestaquia é realizada nas etapas: produção de brotos em minijardim clonal, indução do enraizamento adventício em casa de vegetação climatizada, aclimatização à sombra, crescimento e rustificação, como descrito por Xavier e Wendling (1998), Higashi et al. (2000), Alfenas et al. (2004), Assis et al. (2004) e Xavier et al. (2009). A otimização das operações em cada uma dessas etapas contribui para o sucesso da produção de mudas (FERREIRA et al., 2004).

Ferreira et al. (2004), trabalhando para determinar o tempo ótimo de enraizamento de miniestacas de dois clones de Eucalyptus spp., constataram diferença na velocidade de enraizamento dos propágulos, indicando que o tempo de permanência das miniestacas em casa de vegetação influencia diretamente no porcentual de enraizamento e posteriormente na sobrevivência na casa de sombra.

Durante o processo rizogênico, a anatomia de raízes adventícias envolve a formação de grupos de células meristemáticas, a diferenciação desses grupos de células em primórdios radiciais, e o desenvolvimento e a emergência das novas raízes, incluindo a ruptura de outros tecidos do caule e a formação de conexões vasculares com os tecidos condutores da estaca (HARTMANN et al., 2002). Somente a partir da formação de primórdios radiciais é possível observar o surgimento de raízes.

Considerando que a maioria das empresas do setor florestal brasileiro utiliza a saída de raízes do tubete como critério para a retirada das mudas da casa de vegetação, é possível demonstrar que normalmente há uma tendência em superestimar o tempo de permanência na casa para indução da rizogênese (FERREIRA et al., 2004).

A produção de mudas por miniestaquia em condições climáticas que exigem estruturas para manutenção do controle ambiental necessita de um domínio da técnica para alcançar os resultados desejados (ZANI FILHO e BALLONI, 1988). O ajuste de modelos que expressem o enraizamento dos diferentes materiais genéticos a serem propagados em um viveiro pode minimizar os custos, em razão da otimização do uso das instalações, evitando a permanência das mudas na casa além do tempo necessário, ou a morte de miniestacas em função da retirada destas da casa antes do processo rizogênico se completar.

Dessa forma, os objetivos deste trabalho foram determinar o tempo para o enraizamento de miniestacas de quatro clones de Eucalyptus urophylla $\mathrm{x}$ E. grandis $\left(\mathrm{C}_{1}, \mathrm{C}_{2}, \mathrm{C}_{3}\right.$ e $\left.\mathrm{C}_{4}\right)$ e um híbrido natural de Eucalyptus grandis $\left(\mathrm{C}_{5}\right)$, e ajustar modelos que melhor expressem o comportamento de cada material genético em todo o processo de enraizamento.

\section{MATERIAIS E MÉTODOS}

\subsection{Material experimental}

O trabalho foi realizado no período de agosto a setembro de 2008, no viveiro florestal da empresa Celulose Nipo-Brasileira S A (CENIBRA), localizada no Município de Belo Oriente, Minas Gerais, localizado na região do Vale do Rio Doce, com clima do tipo Cwa (subtropical, chuvoso e mesotérmico), segundo a classificação de Köeppen, latitude de 19¹8’23', S e longitude $42^{\circ} 22^{\prime} 46^{\prime \prime}$ W $\mathrm{W}$ altitude de $363 \mathrm{~m}$. Apresenta precipitação média anual de $1.233 \mathrm{~mm}$, temperatura média anual de $21^{\circ} \mathrm{C}$, com máxima de $27^{\circ} \mathrm{C}$ e mínima de $14^{\circ} \mathrm{C}$.

Foram utilizadas miniestacas de quatro clones de Eucalyptus grandis $\left(\mathrm{C}_{1}, \mathrm{C}_{2}, \mathrm{C}_{3}\right.$ e $\mathrm{C}_{4}=$ Eucalyptus urophylla x E. grandis, e um híbrido natural de Eucalyptus grandis $-C_{5}$ ) neste estudo, coletadas em minicepas estabelecidas em minijardim clonal, com manejo e nutrição de acordo com os procedimentos adotados pela empresa CENIBRA. O critério de seleção desses clones foi baseado, principalmente, nos percentuais médios de enraizamento e na disponibilidade de material vegetativo para o processo de produção de mudas clonais. Foi selecionado um clone com percentual de enraizamento acima de $90 \%$ $\left(C_{1}\right)$, dois entre 80 e $90 \%\left(C_{2}\right.$ e $\left.C_{4}\right)$, e dois com índices de enraizamento entre 60 e $80 \%\left(\mathrm{C}_{3}\right.$ e $\left.\mathrm{C}_{5}\right)$. 


\subsection{Manejo do minijardim clonal}

Conforme a técnica de miniestaquia descrita por Xavier e Wendling (1998), Higashi et al. (2000), Wendling et al. (2000a), Alfenas et al. (2004), Assis et al. (2004) e Xavier et al. (2009), e de acordo com os procedimentos de manejo adotados pela CENIBRA, o minijardim clonal foi constituído de minicepas obtidas do enraizamento de miniestacas, implantadas em canaletas de alvenaria, preenchidas com brita no fundo e areia lavada no restante do espaço. O minijardim foi mantido sob cobertura plástica retrátil.

A irrigação e a nutrição mineral foram efetuadas por sistema automatizado de fertirrigação por gotejamento, conforme procedimentos operacionais adotados pela empresa CENIBRA. A cada três horas, o sistema era acionado, irrigando por $6 \mathrm{~min}$. O excesso da solução nutritiva drenava pelo fundo da canaleta e retornava, pelas tubulações, à caixa de armazenamento da solução, que era monitorada regularmente e trocada a cada 7 dias. Diariamente, foram mensurados a Ec (condutividade elétrica) e o pH da solução.

\subsection{Obtenção, preparo e estaqueamento das miniestacas}

As miniestacas foram coletadas em minicepas do minijardim clonal, com 6 a $8 \mathrm{~cm}$ de comprimento e dois pares de folhas reduzidas à metade de sua dimensão original. Para manter a turgescência do material vegetativo, as miniestacas foram acondicionadas em caixas de isopor, recebendo pulverizações manuais de água em intervalos inferiores a 5 minutos até a etapa de estaqueamento. O período compreendido entre a coleta das miniestacas, seu preparo e o estaqueamento foi sempre inferior a $20 \mathrm{~min}$.

As miniestacas foram estaqueadas da base até aproximadamente um terço de seu tamanho, em substrato composto por uma mistura de casca de arroz carbonizada e vermiculita de granulometria média $(1: 1-v / v)$, enriquecida com $8 \mathrm{~kg} / \mathrm{m}^{3}$ de superfosfato simples, $694 \mathrm{~g} / \mathrm{m}^{3}$ de sulfato de amônio, $208 \mathrm{~g} / \mathrm{m}^{3}$ de cloreto de potássio, $13,9 \mathrm{~g} / \mathrm{m}^{3}$ de sulfato de zinco, $13,9 \mathrm{~g} / \mathrm{m}^{3}$ de sulfato de cobre, $13,9 \mathrm{~g} / \mathrm{m}^{3}$ de sulfato de manganês e $27,8 \mathrm{~g} / \mathrm{m}^{3}$ de ácido bórico. Foram utilizados como recipientes tubetes cônicos de $12 \mathrm{~cm}$ de comprimento e $55 \mathrm{~cm}^{3}$ de capacidade, previamente esterilizados em água quente a $80^{\circ} \mathrm{C} / 30$ seg., conforme método descrito por Alfenas et al. (2004).

\subsection{Avaliações experimentais}

O processo de enraizamento das miniestacas foi realizado em casa de vegetação climatizada e na área de sombreamento do viveiro florestal da CENIBRA. Foram controladas as condições do ambiente da casa de vegetação climatizada, visando garantir temperatura em torno de $27^{\circ} \mathrm{C}$ e umidade relativa do ar acima de $80 \%$. Na área de sombreamento, foi usada tela sombrite $50 \%$.

As miniestacas permaneceram na casa de vegetação por 18 dias, e em seguida, foram transferidas para aclimatização em casa de sombra, onde permaneceram por mais 6 dias. Foram feitas avaliações a cada 3 dias, a contar da data do estaqueamento, até o $24^{\circ}$ dia. Em cada data de avaliação, foram quantificadas as miniestacas com algum grau de modificação, as miniestacas enraizadas, e as miniestacas com raízes maiores que $10 \mathrm{~cm}$ de comprimento, ou seja, aquelas cujas raízes saíam pela base do tubete. Foram consideradas miniestacas modificadas aquelas que apresentaram modificações aparentes que representaram uma predisposição ao enraizamento propriamente dito, como pontos translúcidos na base de miniestacas, intumescimento da base da estaca, formação de calos e pontos de iniciação de raízes.

Em cada data, foram avaliadas 66 miniestacas por clone, seis repetições compostas por 11 miniestacas por parcela, utilizando o delineamento estatístico inteiramente casualizado. Nessas avaliações, as miniestacas eram retiradas do substrato, analisadas e descartadas.

Além da quantificação das características descritas, foi feita avaliação qualitativa do comportamento das miniestacas de cada clone durante o período de estudo. Nesta avaliação, foram examinadas visualmente características como oxidação na base das miniestacas e tombamento durante o enraizamento.

A porcentagem de estacas com algum grau de modificação foi utilizada para o ajuste da melhor função que representasse a distribuição dos dados. A porcentagem de estacas enraizadas e a de estacas com raízes maiores que $10 \mathrm{~cm}$ foram utilizadas para o ajuste da função logística $Y=\alpha\left(1+\beta e^{-\gamma \mathrm{T}}\right)^{-1}$, em que $\boldsymbol{Y}=$ porcentagem de enraizamento ou porcentagem de estacas com raízes maiores que $10 \mathrm{~cm}$, e $\mathbf{T}=$ número de dias após o estaqueamento.

Revista Árvore, Viçosa-MG, v.35, n.4, p.759-767, 2011 
Com base em Ferreira et al. (2004) e de posse da equação obtida com o porcentual de enraizamento de cada clone, foi determinado o potencial máximo de enraizamento $(\alpha)$. As velocidades médias de enraizamento, $Y / T$, e as velocidades diárias foram determinadas, empregando a função $\mathrm{d} Y / \mathrm{d} T=y \times \mathrm{Y}(\alpha-\mathrm{Y}) / \alpha$. As equações foram obtidas pelos programas CurveExpert 1.3 e STATGRAPHICS Plus.

A partir das velocidades de enraizamento ( $Y / T$ e $\mathrm{d} Y / \mathrm{d} T=y \times \mathrm{Y}(\alpha-\mathrm{Y}) / \alpha)$, foram geradas as curvas de Incremento Médio Diário (IMD) e Incremento Corrente Diário (ICD), respectivamente. Essas curvas foram utilizadas como critérios para a retirada das miniestacas da casa de vegetação. As curvas de IMD e ICD tiveram como base a sua aplicação na área de manejo florestal a fim de definir o momento ótimo de corte de um povoamento florestal, como mostrado por Campos e Leite (2006).

As equações obtidas para cada clone foram comparadas, utilizando o procedimento estatístico proposto por Leite e Oliveira (2002), a 5\% de probabilidade.

\section{RESULTADOS}

Para a porcentagem de miniestacas com algum grau de modificação, o modelo que mais se ajustou à distribuição dos dados foi do tipo $\boldsymbol{Y}=(a+b \mathbf{T}) /\left(1+c \mathbf{T}+d \mathbf{T}^{2}\right)$ (Figura 1A), em que $\boldsymbol{Y}=$ porcentual de miniestacas modificadas e $\mathbf{T}=$ número de dias após o estaqueamento. Segundo a tendência de distribuição dos dados de enraizamento (Figura 1B) e a porcentagem de miniestacas com raízes maiores que $10 \mathrm{~cm}$ (Figura 1C), o modelo logístico $\mathrm{Y}=\alpha\left(1+\beta \mathrm{e}^{-\gamma \mathrm{T}}\right)^{-1}$ foi o que apresentou o melhor ajuste para os cinco clones de eucalipto estudados.

De acordo com o procedimento estatístico proposto por Leite e Oliveira (2002) e com base nas curvas obtidas (Figura 1), é possível distinguir diferenças de comportamento dos clones avaliados durante o processo rizogênico, indicando diferenças de velocidade de resposta das miniestacas, quando submetidas ao estímulo de enraizamento.

A velocidade de enraizamento mais rápida foi do clone $\mathrm{C}_{1}$, que apresentou também a maior porcentagem de raízes fora do tubete aos 18 dias após o estaqueamento. Logo aos três dias após o estaqueamento, cerca de 30\% das miniestacas deste clone já apresentavam alguma modificação que indicava o enraizamento posterior. Aos nove dias, quase $90 \%$ das miniestacas já estavam enraizadas e, aos 18 dias, foi observado este porcentual de miniestacas com raízes maiores que $10 \mathrm{~cm}$ (Figura 2B).

As miniestacas do clone $\mathrm{C}_{5}$, nove dias após terem sido estaqueadas, ou seja, logo após o aparecimento das modificações, se encontravam mais inclinadas, comparativamente às miniestacas dos demais clones (Figuras 2C e 2D), favorecendo o contato da parte aérea com o substrato. Também durante o processo rizogênico do clone $\mathrm{C}_{3}$, foi possível notar a tendência de oxidação da base de suas miniestacas, o que matou muitas antes do enraizamento completo (Figura 2E). Aquelas que sobreviveram, tiveram a formação de raízes acima da região oxidada (Figura 2F).

Os clones $\mathrm{C}_{2}$ e $\mathrm{C}_{4}$ também apresentaram menor velocidade de enraizamento, quando comparados ao clone $C_{1}$ (Figura 3), porém esta diferença foi compensada pelo alto porcentual final de enraizamento (24 dias) de ambos, aproximadamente 90\%. Juntamente com o clone $\mathrm{C}_{5}$, eles possuem curvas de enraizamento muito parecidas, no entanto as miniestacas do clone $\mathrm{C}_{2}$ apresentaram maior tendência em formar calos (Figura 2G).

Com base no critério de seleção dos materiais genéticos, constatou-se que, de forma geral, os índices finais de enraizamento das miniestacas de cada clone apresentaram-se dentro dos intervalos porcentuais alcançados pela CENIBRA.

\section{DISCUSSÃO}

Pela observação das curvas de enraizamento (Figura 1), é possível notar que as peculiaridades apresentadas por miniestacas dos clones $C_{3}$ e $C_{5}$, durante o período em que estas permaneceram na casa de vegetação climatizada, foram alguns dos fatores que causaram o menor desempenho desses clones durante o enraizamento.

Com base nas curvas e pelas estimativas do parâmetro “ $\gamma$ ”, é possível constatar que houve diferenças na velocidade de enraizamento dos clones estudados. Dessa maneira, o esperado é que o tempo mínimo de permanência das miniestacas na casa de vegetação também seja diferente. Para o clone $C_{1}$, além de maior potencial de enraizamento adventício, observado pelo parâmetro “ $\alpha$ ” (97,6\%), que expressa o máximo possível que se pode atingir nas condições estudadas, a curva é mais inclinada, provocando 

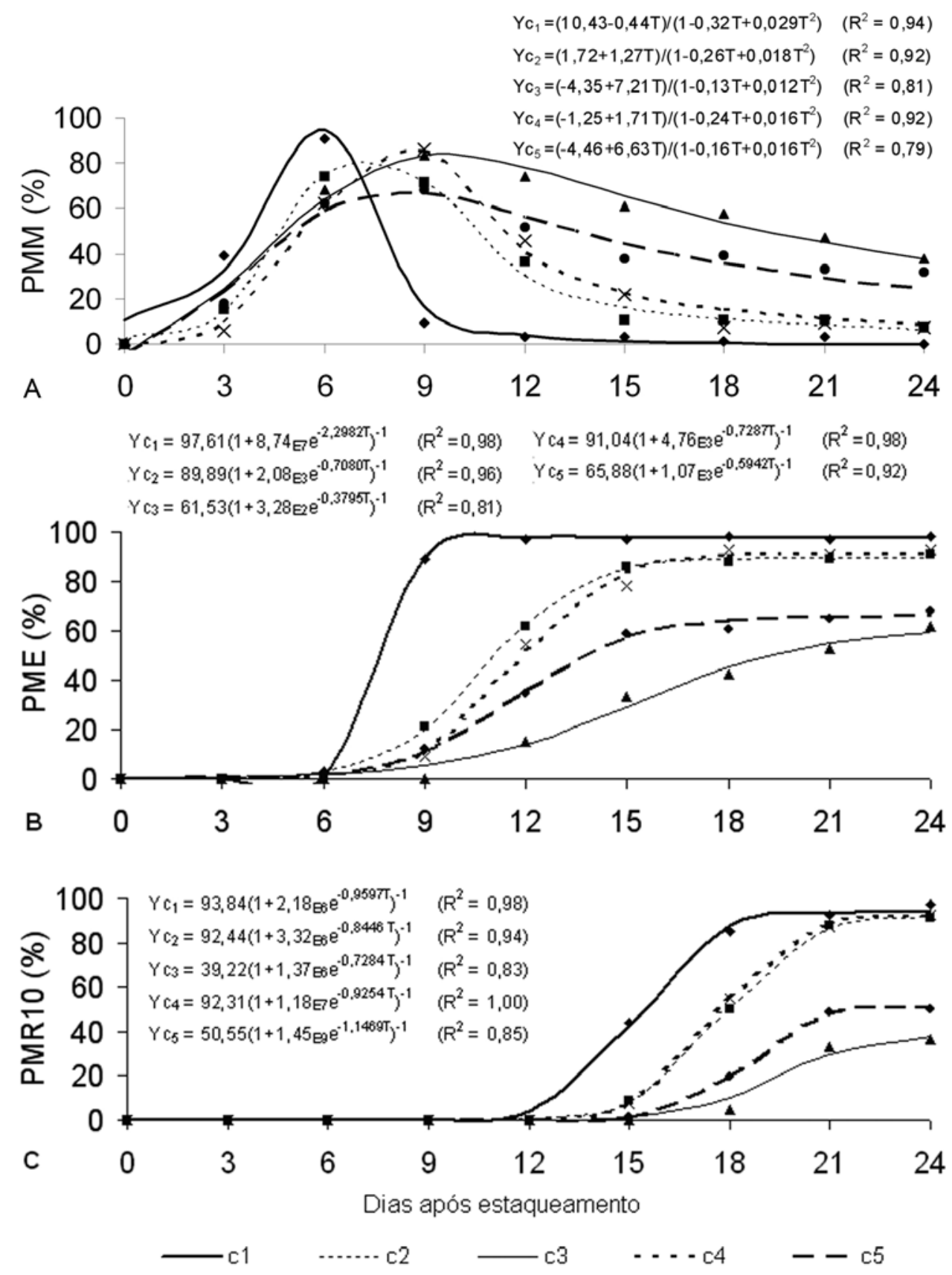

Figura 1 - Enraizamento de miniestacas em cinco clones híbridos de Eucalyptus grandis $\left(\mathrm{C}_{1}, \mathrm{C}_{2}, \mathrm{C}_{3}\right.$ e $\mathrm{C}_{4}=$ Eucalyptus urophylla x E. grandis e $\mathrm{C}_{5}=$ híbrido natural de Eucalyptus grandis), em função do tempo após o estaqueamento. A: Porcentagem de miniestacas modificadas (PMM); B: Porcentagem de miniestacas enraizadas (PME); C: Porcentagem de miniestacas com raízes maiores que $10 \mathrm{~cm}$ (PMR10).

Figure 1 - Minicutting rooting of five Eucalyptus grandis hybrids clones $\left(C_{1}, C_{2}, C_{3}\right.$ and $C_{4}=$ Eucalyptus urophylla $\times \boldsymbol{E}$. grandis and $C_{5}=$ Eucalyptus grandis natural hybrid), in function of the time after striking. A: Percentage of modified minicuttings (PMM); B: Percentage of rooted minicuttings (PME); C: Percentage of minicuttings with roots longer than $10 \mathrm{~cm}$ (PMR10). 

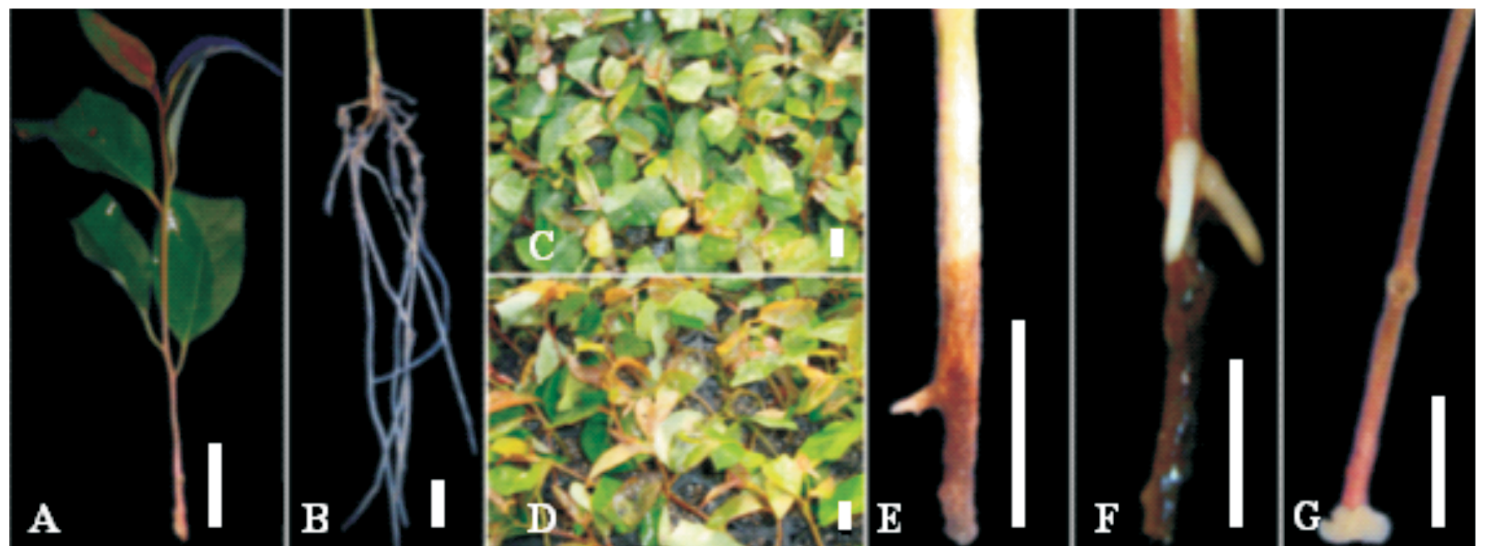

Figura 2 - Detalhes do processo rizogênico em cinco clones de Eucalyptus spp. A: Miniestaca do clone $\mathrm{C}_{4}$; B: Detalhe do sistema radicular em miniestaca do clone $\mathrm{C}_{1}$, aos 18 dias; $\mathbf{C}$ : Miniestacas do clone $\mathrm{C}_{2}$ na posição ereta; $\mathbf{D}$ : Miniestacas do clone $\mathrm{C}_{5}$ tombadas; E: Morte de miniestaca do clone $\mathrm{C}_{3}$ devido ao processo de oxidação; F: Formação de raízes acima da porção oxidada da miniestaca no clone $\mathrm{C}_{3}$ e $\mathbf{G}$ : Miniestaca do clone $\mathrm{C}_{2}$ com calo $($ Barra $=1 \mathrm{~cm})$.

Figure 2 - Details of the rooting process of five Eucalyptus spp. clones. A: $C_{4}$ clone minicutting; B: Detail of the root system in $C_{1}$ clone minicutting at 18 days; $\boldsymbol{C}: C_{2}$ clone minicuttings at the erect position; $\boldsymbol{D}:$ Tumbled $C_{5}$ clone minicuttings; $\boldsymbol{E}$ : Death of $\mathrm{C}_{3}$ clone minicutting due to the oxidation process; $\mathbf{F}$ : Formation of roots above the rusted portion of the minicutting in the $C_{3}$ clone and $G: C_{2}$ clone minicutting with callus (Bar $\left.=1 \mathrm{~cm}\right)$.

a ocorrência precoce do ponto de inflexão, quando comparado com os demais clones. Em contrapartida, o clone $\mathrm{C}_{3}$ apresenta o menor potencial de enraizamento adventício (61,5\%), e possui uma curva menos inclinada, que, consequentemente, acarreta ponto de inflexão mais tardiamente (Figura 3).

De acordo com o critério de velocidade de enraizamento, é possível encontrar as respectivas datas em que esta característica foi máxima para cada clone, ou seja, momentos em que, cada curva de incremento corrente diário (ICD-E) apresentou seu valor máximo. Os clones $\mathrm{C}_{2}, \mathrm{C}_{4}$ e $\mathrm{C}_{5}$ apresentaram comportamentos rizogênicos muito parecidos, com seus pontos de máxima velocidade de enraizamento próximos (11-12 dias após o estaqueamento). Nos extremos, observa-se o clone $\mathrm{C}_{1}$ com uma taxa inicial de enraizamento superior à dos demais, apresentando seu ápice já aos oito dias, e o clone $\mathrm{C}_{3}$ que chega à velocidade máxima de enraizamento após 15 dias do estaqueamento.

A observação do ponto em que ocorre a máxima velocidade de enraizamento pode servir como critério para a retirada das miniestacas da casa de vegetação. No entanto, uma miniestaca recém-enraizada pode não possuir condições plenas para se desenvolver em ambientes adversos com relação à umidade e temperatura, mais controláveis dentro das casas de vegetação climatizadas.

Revista Árvore, Viçosa-MG, v.35, n.4, p.759-767, 2011
Observando a Figura 1, é possível perceber que há um intervalo entre o enraizamento propriamente dito e a saída das raízes pela base do tubete, ou seja, raízes maiores que $10 \mathrm{~cm}$. O critério mais utilizado, atualmente, para a retirada das miniestacas da casa de vegetação é a observação da saída de raízes na parte inferior do tubete, o que não deixa de superestimar o tempo ótimo necessário. Por outro lado, curvas do tipo velocidade de enraizamento não levam em consideração o tamanho mínimo das raízes para permitir o desenvolvimento e a formação da futura muda. Dessa forma, é necessária a identificação de um ponto ótimo nesse intervalo, que permita utilizar as estruturas de propagação de forma mais eficiente num processo de propagação clonal de Eucalyptus.

Outro critério útil para a decisão da retirada das miniestacas enraizadas do interior da casa de vegetação considera o intercepto entre as curvas de incremento médio diário (IMD) e incremento corrente diário (ICD) do enraizamento (Figura 4), em analogia ao realizado nos trabalhos de biometria florestal. Por ser um critério menos rigoroso (FERREIRA et al., 2004), acaba aumentando o tempo de permanência das miniestacas na casa de vegetação em relação ao critério anterior, o que permite maior crescimento do sistema radicial das miniestacas. 


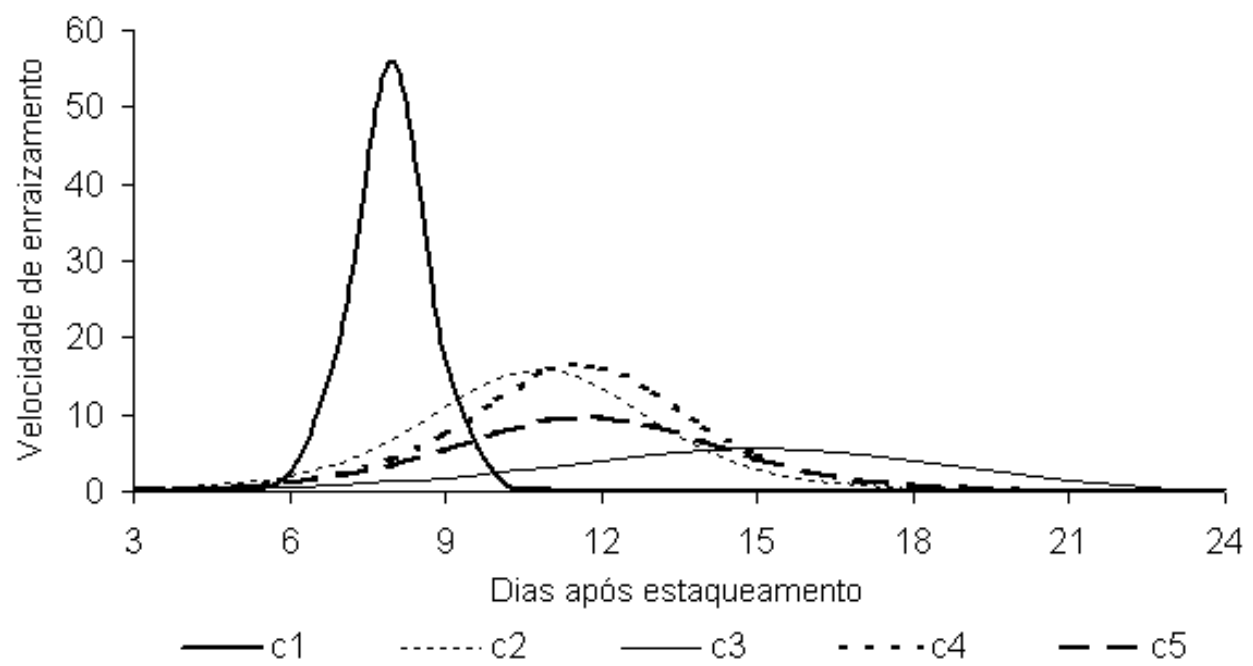

Figura 3 - Velocidade de enraizamento (miniestacas por dia) em cinco clones híbridos de Eucalyptus grandis $\left(\mathrm{C}_{1}, \mathrm{C}_{2}, \mathrm{C}_{3}\right.$

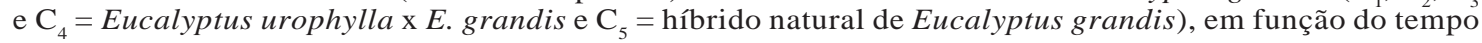
após o estaqueamento.

Figure 3 - Rooting speed (minicuttings per day) of five clones of Eucalyptus grandis hybrids $\left(C_{1}, C_{2}, C_{3}\right.$ and $C_{4}=$ Eucalyptus urophylla $\times$ E. grandis and $C_{5}=$ Eucalyptus grandis natural hybrid), in function of the time after plantation.

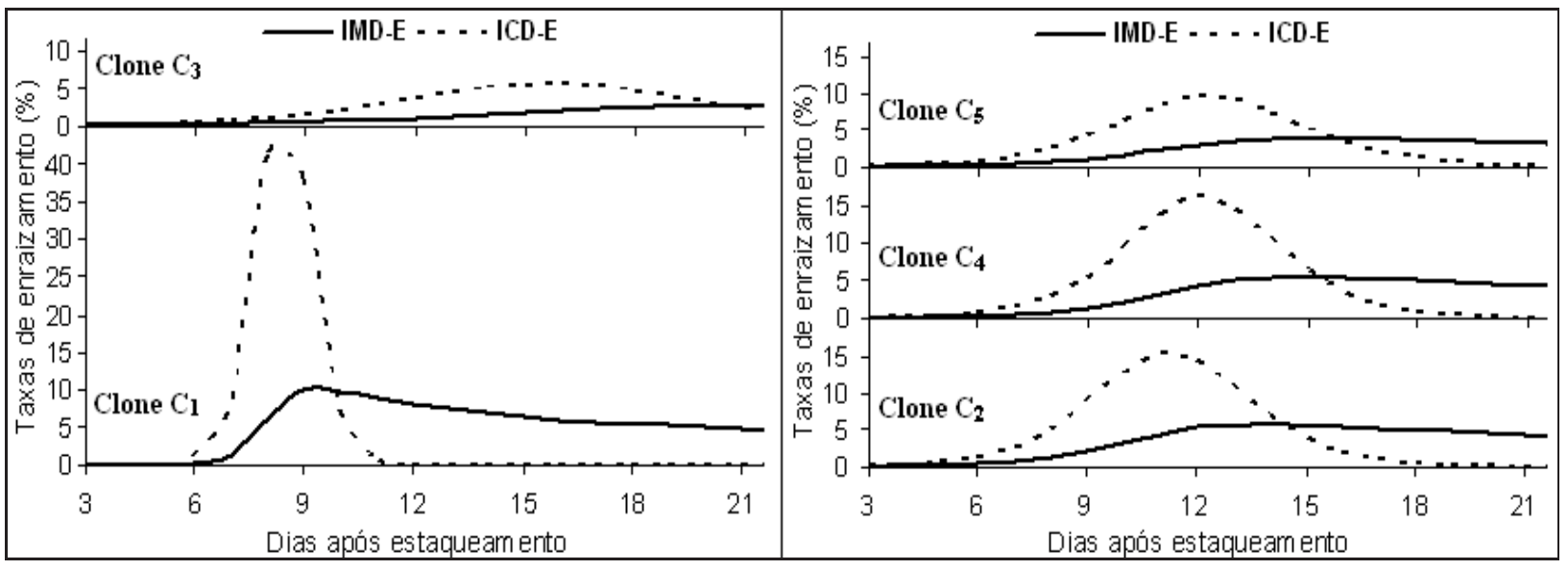

Figura 4 - Incremento médio diário (IMD-E) e incremento corrente diário (ICD-E) do enraizamento de cinco clones híbridos de Eucalyptus grandis $\left(\mathrm{C}_{1}, \mathrm{C}_{2}, \mathrm{C}_{3}\right.$ e $\mathrm{C}_{4}=$ Eucalyptus urophylla $\mathrm{x}$ E. grandis e $\mathrm{C}_{5}=$ híbrido natural de Eucalyptus grandis), em função do tempo após o estaqueamento.

Figure 4-Daily average increase (IMD-E) and daily current increase (ICD-E) of the rooting in five clones of Eucalyptus grandis hybrids $\left(C_{1}, C_{2}, C_{3}\right.$ and $C_{4}=$ Eucalyptus urophylla $\times$ E. grandis and $C_{5}=$ Eucalyptus grandis natural hybrid), in function of the time after striking.

A utilização, em si, do intercepto entre curvas de IMD e ICD do enraizamento também não considera o tamanho das raízes. No entanto, por ser menos rigoroso quanto ao tempo mínimo de permanência em casa de vegetação, colabora para o melhor enraizamento das miniestacas e posterior sobrevivência dessas na área de sombra. É recomendável a utilização do intercepto entre as curvas de IMD e ICD do que a curva de velocidade do enraizamento, visando à otimização do enraizamento adventício das miniestacas dos clones avaliados, 
concordando assim com as considerações apontadas por Ferreira et al. (2004), quanto à otimização do enraizamento de miniestacas de dois clones de Eucalyptus spp.

A utilização do ponto de intercepto mantém praticamente a mesma ordem de retirada dos clones, porém com alguns dias de atraso em relação ao critério anterior. O primeiro clone a ser retirado da casa de vegetação é o $C_{1}$ aos 10 dias após o estaqueamento; em seguida, os clones $\mathrm{C}_{2}, \mathrm{C}_{4}$ e $\mathrm{C}_{5}(14,15$ e 16 dias, respectivamente) e, finalmente, o clone $\mathrm{C}_{3}$ aos 20 dias.

Com base no atual critério de decisão sobre a retirada das miniestacas enraizadas de dentro da casa de vegetação climatizada, utilizado por muitas empresas do setor florestal, ao mesmo tempo em que um material genético pode ser retirado antes do momento ótimo, outros genótipos podem permanecer por tempo além do necessário, indisponibilizando as estruturas de propagação para novos ciclos. Uma casa de vegetação, por exemplo, com ciclo médio de 20 dias (18 dias de enraizamento e 2 dias de manutenções) possibilita a realização de 18,3 ciclos por ano. Com a redução de dois dias em cada ciclo (clone $\mathrm{C}_{5}$ ), esta casa possibilitará a realização de 20,3 ciclos, um aumento de $11 \%$. No entanto, com os resultados obtidos a partir dos dados de enraizamento do clone $\mathrm{C}_{1}$ (10 dias de enraizamento mais 2 dias de manutenções), seria possível a realização de 30,4 ciclos em um ano, aumentando a capacidade produtiva em $66 \%$.

Dessa forma, com base na metodologia utilizada e nos resultados obtidos, o estaqueamento, em uma mesma casa de vegetação, de materiais genéticos que possuem curvas de enraizamento semelhantes otimiza as estruturas de propagação, visto serem retirados no momento mais adequado. No entanto, estudos como este também devem ser realizados em outras épocas do ano, pois, como mencionado por Higashi et al. (2000), Wendling et al. (2000b), Hartmann et al. (2002), Ferreira et al. (2004) e Xavier et al. (2009), há interferência de fatores climáticos no processo rizogênico, podendo elevar ou diminuir o tempo de permanência na casa de vegetação.

\section{CONCLUSÕES}

Com base nos resultados obtidos com o enraizamento de miniestacas dos cinco clones de Eucalyptus spp. avaliados, conclui-se que há diferenças no desempenho desses materiais genéticos no processo rizogênico. A identificação do ponto ótimo de enraizamento das miniestacas permite estabelecer a velocidade do processo rizogênico e, assim, programar de forma mais eficiente a utilização da casa de vegetação. Para otimizar o tempo de enraizamento de miniestacas, sugere-se o intercepto entre curvas de IMD e ICD como critério para retirada dos clones da casa de vegetação.

\section{REFERÊNCIAS}

ALFENAS, A. C. et al. Clonagem e doenças do eucalipto. Viçosa, MG: Universidade Federal de Viçosa, 2004. 422p.

ASSIS, T. F.; FETT NETO, A. G.; ALFENAS, A. C. Current techiniques and prospects for the clonal propagation of hardwoods with emphasis on Eucalyptus. In: WALTERS, C.; CARSON, M. (Eds.) Plantation forest biotechnology for the $21^{\text {st }}$ century. Kerala: Research Signpost, 2004. p.303-333.

CAMPOS, J. C. C.; LEITE, H. G. Mensuração

florestal: perguntas e respostas. 2.ed. Viçosa,MG: Universidade Federal de Viçosa, 2006. 470p.

FERREIRA, E. M. et al. Determinação do tempo ótimo do enraizamento de miniestacas de clones de Eucalyptus spp. Revista Árvore, v.28, n.2, p.183-187, 2004.

HARTMANN, H. T. et al. Plant propagation: principles and practices. 7.ed. New Jersey: PrenticeHall, 2002. 880p.

HIGASHI, E. N.; GONÇALVES, A. N. Uso de ácido indolbutírico no enraizamento de eucaliptos. IPEF Notícias, v.24, n.148, p.4-5, 2000.

HIGASHI, E. N.; SILVEIRA, R. L. A.; GONÇALVES, A. N. Propagação vegetativa de Eucalyptus: princípios básicos e a sua evolução no Brasil. Piracicaba: IPEF, 2000. 11p. (Circular Técnica, 192).

LEITE, H. G.; OLIVEIRA, F. H. T. Statistical method to test the identity of analytical methods.

Communications in Soil Science and Plant Analysis, v.6/7, p.1-22, 2002.

WENDLING, I. et al. Efeito do regulador de crescimento AIB na propagação de clones de Eucalyptus spp. por miniestaquia. Revista Árvore, v.24, n.2, p.187-192, 2000a. 
WENDLING, I. et al. Propagação clonal de híbridos de Eucalyptus spp. por miniestaquia. Revista Árvore, v.24, n.2, p.181-186, 2000b.

XAVIER, A.; WENDLING, I. Miniestaquia na clonagem de Eucalyptus. Viçosa, MG: SIF, 1998. 10p. (Informativo Técnico SIF, 11).
XAVIER, A.; WENDLING, I.; SILVA, R. L.

Silvicultura clonal: princípios e técnicas. Viçosa, MG: Editora UFV, 2009. 272 p.

ZANI FILHO, J.; BALLONI, E. D. Enraizamento de estacas de Eucalyptus: efeitos do substrato e do horário de coleta do material vegetativo. IPEF, n.40, p.39-42, 1988. 